In the unusual event of failure to remove a foreign body with a bronchoscope, a thoracotomy will be necessary; bronchotomy, segmental resection, or lobectomy may be necessary. Complications of inhaled foreign bodies include asphyxia, cardiac arrest, life-threatening dyspnoea, laryngeal oedema, and pneumothorax. Late complications such as pneumonia, lung abscess, or bronchiectasis may occur when a foreign body has been retained for a number of weeks. Early bronchoscopy may, indeed, be life saving and may prevent permanent disability; but the first requirement is a high index of suspicion that the patient may have inhaled something into his lungs.

1 Aytac A, Yurdakul Y, Ikizler C, Olga R, Saylam A. Inhalation of foreign bodies in children. Report of 500 cases. F Thorac Cardiovasc Surg 1977;74:145-51.

2 Dudgeon DL, Parker FB, Frittelli G, Rabuzzi DD. Bronchiectasis in pediatric patients resulting from aspirated grass inflorescences. Arch Surg 1980;115:979-83.

3 Abdulmajid OA, Ebeid AM, Motaweh MM, Kleibo IS. Aspirated foreign bodies in the tracheobronchial tree: report of 250 cases. Thorax $1976 ; 31: 635-40$.

${ }^{4}$ Kim IG, Brummitt WM, Humphrey A, Siomra SW, Wallace WB. Foreign body in the airway: a review of 202 cases. Laryngoscope 1973; $83: 347-54$.

${ }^{5}$ Ross AHM, McCormack RJM. Foreign body inhalation. $\boldsymbol{f} \boldsymbol{R}$ Coll Surg Edinb 1980;25:104-9.

- Cotton EK, Abrams G, Vanhoutte J, Burrington J. Removal of aspirated foreign bodies by inhalation and postural drainage. A survey of 24 cases. Clin Pediatr (Phila) 1973;12:270-6.

${ }^{7}$ Hunsicker RC, Gartner WS. Fogarty catheter technique for removal of endobronchial foreign body. Arch Otolaryngol 1977;103:103-4.

8 Elhassani NB. Aspirated trachebronchial foreign bodies in infants. Analysis of 50 cases. $7 R$ Coll Surg Edinb 1978;23:310-4.

9 Keith FM, Charrette EJ, Lynn RB, Salerno TA. Inhalation of foreign bodies by children: a continuing challenge in management. Can Med Assoc $\mathcal{F} 1980 ; 122: 52,55-7$.

10 Chatterji $S$, Chatterji $P$. The management of foreign bodies in air passages. Anaesthesia $1972 ; 27: 390-5$.

11 Ritter FN. Questionable methods of foreign body treatment. Ann Otol Rhinol Laryngol $1974 ; 83: 729-33$.

12 Daniilidis J, Symeonidis B, Triaridis K, Kouloulas A. Foreign body in airways-review of 90 cases. Arch Otolaryngol 1977;103:570-3.

\section{Why not vaccinate against malaria?}

A recent review ${ }^{1}$ of malaria worldwide pointed out that over one-fifth of the people living in the historical endemic areas (2128 million or $65 \%$ of the total world population) were still exposed to the risk of infection. Matters are worst in Africa, where nearly three-quarters of the population is at risk, and where the main species is the potentially lethal malignant tertian parasite Plasmodium falciparum. A gradual collapse of malaria-control operations led to the resurgence of transmission (at first mainly $P$ vivax) in India to an annual total of over six million cases in the mid-1970s. The malaria eradication campaign sponsored by WHO in the 1950s did succeed in virtually elimating malaria from Europe, the Asian part of the USSR, North America, and Australia. In other areas a variety of problems, some socioeconomic, others technical, have blocked progress and forced a major change in the strategy ${ }^{2}$ of controlling this disease.

Malaria remains a prime obstacle to progress in many developing countries and a source of morbidity and mortality even in non-endemic countries-in England, Wales, and Northern Ireland 1670 cases of imported malaria were recorded in 1980 , with nine deaths. ${ }^{3}$ Among the technical problems facing the health authorities is resistance of malaria vectors to insecticides and of the parasites (especially $P$ falciparum) to antimalarial drugs. Considerable effort is being put into developing new insecticides and drugs and into research into the mechanisms of action of and resistance to such compounds: partly under the auspices of the WHO/UNDP/World Bank Special Programme for Research and Training in Tropical Diseases. ${ }^{4}$

The remarkable success of the WHO campaign for eradicating smallpox has prompted many people to pose the question "Why not vaccinate against malaria?" Unfortunately, the two conditions are utterly different. Unlike the virus of smallpox, the protozoal organisms causing malaria undergo a complex series of metamorphoses both within and outside the human host. The infective stages that are injected when a female Anopheles mosquito bites do stimulate an immune response during the brief period that they remain in the circulation, but this response appears to be largely humoral and lasts only a few months. ${ }^{56}$ People living in endemic areas who are continuously exposed to infected mosquitos remain susceptible to infection. Nevertheless, volunteers can be protected against homologous challenge for a few months by inoculation with irradiated sporozoites. ${ }^{78}$ The use of adjuvants does not apparently improve this protection. The failure of thymus-deprived mice to survive such challenge suggests that cell-mediated effector mechanisms are also concerned, but whether these observations are relevant to human disease remains open to question. In practical terms, the problems in the mass production of sporozoites for a vaccine are probably insurmountable, quite apart from the difficulties of conserving and transporting such a vaccine.

Most attention has been focused, therefore, on the mechanisms of immunity against the stages of malaria parasites in the blood. ${ }^{5}$ Both humoral and cellular effector mechanisms operate against the different stages of the parasites. IgG and IgM have been shown to block the invasion of fresh erythrocytes by the merozoites that are liberated when the plasmodial schizonts mature and burst from their host red cells. Merozoites are the logical forms to use for vaccination since they are free of contaminating host-cell substance that might induce an autoimmune response. New techniques have been developed for the laboratory cultivation of $\boldsymbol{P}$ falciparum $^{9}$ and, while these are not yet at the stage of mass production that would be required before a merozoite-based vaccine could be exploited, they have opened the way to extensive studies on vaccine development. Several workers have now been able to protect animals (especially the South American Owl Monkey, Aotus trivirgatus) against otherwise lethal challenge with $P$ falciparum. Nevertheless, as was found in earlier attempts to protect rhesus monkeys against blood stages of $\boldsymbol{P}$ knowlesi, use of an adjuvant together with the antigenic parasite material is essential, and up to now the best results have come from substances, such as Freund's complete adjuvant and saponin, that are unacceptable for human use. ${ }^{10}$ Moreover, in these studies on animals protection has rarely been complete even with the use of modern adjuvants, and the outcome has been unpredictable from one animal to another. A major problem facing all attempts to develop malaria vaccines is our ignorance of the relevance of data obtained from work on the available animals (mainly rodent and simian hosts and parasites) to the response that might be expected in man. ${ }^{11}$

These are only a few of the difficulties in the development of a malaria vaccine before we even reach the major questions that must be posed before clinical trials. Clear guidelines have been laid down for the criteria that a vaccine must meet before 
it is first given to volunteers. ${ }^{12-14}$ The drawback with all approaches made is that they have been based on the use of complex organisms and not pure antigens. Other than one parasite protein that has been found to protect ducks against $P$ lophurae, ${ }^{15}$ few data are available from research in vivo to indicate whether single antigens could be of value. Fortunately, attention is now being directed to the use of monoclonal antibodies to identify immunogenic antigens in malaria parasites, and several have recently been described both in rodent parasites ${ }^{16}$ and in $P$ falciparum. ${ }^{17}$ Future efforts will probably be focused on the application of this new technology and the production of protective sporozoite or merozoite antigens by DNA recombinant procedures. Indeed, this is the most likely route to a practical vaccine for use in man. There is, however, a long way to go, and we should be deceiving ourselves if we believed that a vaccine was, as some have suggested, just round the corner. It would also be a great mistake to assume that malaria will ever be controlled in whole populations (as distinct from individuals) by any single measure. Control programmes need to take into account the best available antivector measures, drugs, vaccines (including, perhaps, an antigamete component to interrupt further transmission $\left.{ }^{18}\right)$, and health education tailor made for any given area. The biggest need may still be for well-trained malariologists.

${ }^{1}$ Wernsdorfer W. The importance of malaria in the world. In: Kreier JP, ed. Malaria. Vol 3. Epidemiology, chemotherapy, morphology, and metabolism. London: Academic Press, 1890:1-93.

2 World Health Organisation. WHO Expert Committee on Malaria, 17th Report. Geneva: WHO, 1979. (Technical Report Series 640.)

${ }^{3}$ Public Health Laboratory Service. Malaria in the United Kingdom: 1980.
Colindale: Communicable Disease Surveillance Centre, 1981:1. (Communicable Disease Report CDR 81/13.)

United Nations Development Programme/World Bank/World Health Organisation. Special programme for research and training in tropical diseases. Fourth annual report. 1 fuly 1979-30 fune 1980. Geneva: 1980.

Cohen S. Immunity to malaria. Proc R Soc Lond (B) 1979;203:323-45.

'Cochrane AH, Nussenzweig RS, Nardin EH. Immunisation against sporozoites. In : Kreier JP, ed. Malaria. Vol 3. Immunology and immunisation. London: Academic Press, 1980:163-202.

Clyde DF, McCarthy V, Miller RM, Woodward WE. Immunisation of man against falciparum and vivax malaria by use of attenuated sporozoites. Am F Trop Med Hyg 1975;24:397-401.

${ }^{8}$ Rieckman KH, Beaudoin RL, Cassells JS, Sell KW. Use of attenuated sporozoites in the immunisation of human volunteers against falciparum malaria. Bull WHO 1979;57 :suppl 1:261-5.

9 Trager W, Jensen JB. Cultivation of erythrocytic and exoerythrocytic stages of plasmodia. In: Kreier JP, ed. Malaria. Vol 2. Pathology, vector studies, and culture. London: Academic Press, 1980:271-319.

${ }^{10}$ Siddiqui WA. Immunisation against asexual blood-inhabiting stages of plasmodia. In: Kreier JP, ed. Malaria. Vol 3. Immunology and immunisation. London: Academic Press, 1980:231-62.

${ }^{11}$ Desowitz RS, Miller LH. A perspective on malaria vaccines. Bull WHO $1980 ; 58: 897-908$.

${ }^{12}$ McGregor IA. Basic considerations concerning field trials of malaria vaccines in human populations. Bull WHO 1979;57,suppl 1:267-71.

${ }^{13}$ Diggs CL. Prospects for development of vaccines against Plasmodium falciparum infection. In: Kreier JP, ed. Malaria. Vol 3. Immunology and immunisation. London: Academic Press, 1980:299-315.

${ }^{14}$ Anonymous. Summary of plenary and working group discussions. The production and purification of malaria antigens in culture. Bull WHO $1979 ; 57$, suppl $1: 277-90$.

${ }^{15} \mathrm{Kilejian}$ A. Histidine-rich protein as a model malaria vaccine. Science 1978;201:922-4.

${ }^{16}$ Freeman RR, Trejdosiewicz AJ, Cross GAM. Protective monoclonal antibodies recognising stage-specific merozoite antigens of a rodent malaria parasite. Nature $1980 ; \mathbf{2 8 4}: 336-8$.

${ }^{17}$ Perrin LH, Ramirez E, Lambert PH, Miescher PA. Inhibition of $\mathbf{P}$ falciparum growth in human erythrocytes by monoclonal antibodies. Nature 1981;289:301-3.

${ }^{18} \mathrm{Gwadz}$ RW, Green I. Malaria immunisation in rhesus monkeys: a vaccine effective against both the sexual and asexual stages of Plasmodium knowlesi. F Exp Med 1978;148:1311-23.

\section{Doctors' pay}

In the 20 years since the Pilkington Royal Commission conceived the independent review body system for deciding NHS doctors' and dentists' pay ${ }^{1}$ governments have substantially interfered with recommended awards on two occasions, in $1966^{2}$ and $1970 .^{3}$ The $1981-2$ review $^{4}$ makes the third occasion and the first for a Conservative administration. The Government's decision to cut the Review Body's 9\% (average) recommended increase for doctors (p 1722) to $6 \%$ was given in person by the Prime Minister to the Chairman of Council of the BMA on 15 May. The reasons for this decision were published in a Parliamentary reply ( $p$ 1722). Doctors will have to judge whether these match up to Pilkington's declaration that "while the Government cannot abrogate its functions and responsibility for ultimate decisions, we are insistent that the recommendations of the Review Body must only very rarely and for most obviously compelling reasons be rejected." The Government's determination to control inflation and reduce spending in the public sector is well known. To achieve this end it has among other actions modified the outcome of the "Top salaries" review and resisted the civil servants' pay claim for nearly three months. In declaring its intention to hold doctors' pay within the NHS's $6 \%$ cash limits the Government has implied that to do otherwise would affect services to the patients. Even so, many doctors will be worried by contradictions in the Government's approach to the whole question of public sector pay and by the fact that in its report the Doctors' and Dentists' Review Body took into account "national economic considerations," including the NHS's 6\% cash limits.

The Review Body's chairman, Sir Robert Clark, and his colleagues appear to have taken the Government's decision stoically and are still in place, which should encourage the profession to "consider the Government's decision ... in a responsible manner," as the BMA's statement ( $p$ 1723) after the meeting with the Prime Minister put it. As to the report it would be a pity if in any arguments about the final outcome of the award the contents were relegated to history, for, while parts will not please doctors, there is much useful analysis and valuable comment in what is a clearly written document. The authors have obviously thought carefully about the profession's remuneration, expenses, and pensions, as well as analysing in the introduction one difficult general aspect of their task-namely, the "overlap" between their function as an independent body "charged with making recommendations for the whole remuneration structure" and the function of the profession's representatives and the Health Departments in negotiating changes in contractual terms and conditions of service. "Cases arise," states the report, "where the professions and the departments, although agreed on the desirability of a change, do not agree on its likely cost, on whether the cost should be offset or 'new money' provided, or on the way in which offsetting (if agreed) should be achieved." In proposing 